\title{
The Anatomy of a Successful Caribbean Substance Abuse Training Programme
}

\author{
SD Reid ${ }^{1}$, E Downes $^{2}$, A Khenti ${ }^{3}$
}

\begin{abstract}
Objectives: This paper describes the components of the Caribbean Institute on Alcoholism and Other Drug Problems (CARIAD), a long-standing substance abuse training programme. It seeks to explain how certain strategies and pedagogic techniques may be contributing to its success.

Methods: Authors deconstruct the core elements of CARIAD to demonstrate how the programme effectively meets the characteristics of a community of practice. The processes used to develop the learning community and the specific pedagogic strategies and techniques that foster collaborative knowledge construction and sharing are described.

Results: Caribbean Institute on Alcoholism and Other Drug Problems brings together a multidisciplinary, multi-national group of individuals with interest in substance abuse. The programme provides a range of formal and informal learning activities which focus on sharing best practices and creating new sociocultural relevant knowledge to advance the domain of professional practice in substance abuse. The components of CARIAD promote interactivity, rapid bonding and a sense of identity. Caribbean Institute on Alcoholism and Other Drug Problems provides a unique platform for cultural sharing that gives participants an opportunity to reveal insights into local and regional expressions of substance abuse challenges. Participants, however, recognize the absence of structured continuity and the diminution of what could be accomplished by graduates over time.

Conclusion: The success of CARIAD as a regional learning platform may be related to its success as a Caribbean community of practice for substance abuse. Caribbean Institute on Alcoholism and Other Drug Problems would do well to sustain the community of practice, generating and maintaining ongoing participation and collaboration among graduates. This can potentially serve to create new strategies for advancing the region in the area of substance abuse.
\end{abstract}

Keywords: Alcohol and drug abuse training, CARIAD, Caribbean community of practice, substance abuse training

WIMJ Open 2015; 2 (1): 41

\section{INTRODUCTION}

Substance abuse is a serious public health issue in the Caribbean for reasons related to history, geography and socio-economic risk factors. The Caribbean has long been a global source of rum production, with the rum trade constituting an important sector of the economy for many countries in the region. Rum remains readily affordable and is fully integrated into the region's diverse cultures. Heavy episodic drinking characterizes the Caribbean lifestyle. The cultivation of marijuana, while illegal, has followed a similar trajectory of cultural integration and affordability. Geographically located along the transhipment route of other illicit drugs such as crack cocaine, the Caribbean islands have, since the 1970s, also experienced an increasing accessibility

From: ${ }^{1}$ Department of Psychiatry, The University of the West Indies, St Augustine, Trinidad and Tobago, ${ }^{2}$ Department of Education, Centre for Addiction and Mental Health, Toronto, Canada and ${ }^{3}$ Office of Transformative Global Health, Centre for Addiction and Mental Health, Toronto, Canada.

Correspondence: Dr S Reid, Department of Psychiatry, The University of the West Indies, St Augustine, Trinidad and Tobago. E-mail: reid.dr@gmail.com to these drugs and a resulting chronic crack cocaine epidemic.

Due to the readily available substances, supply and demand reduction and education are vitally important in the prevention of substance abuse and the associated public health challenges. Since the 1950s, supply and demand reduction interventions in the Caribbean have included legislative and fiscal controls, education, treatment and the provision of alternative healthy lifestyles. With Eldra Schulterbrandt, Professor Michael Beaubrun inaugurated the Caribbean Institute on Alcoholism in 1974 in a joint effort to address the region's learning and training needs. This institute later expanded in 1980 to become the Caribbean Institute on Alcoholism and Other Drug Problems (CARIAD) with a mandate for all psychoactive drugs. The objectives of the Institute have since been: 1) to raise the level of awareness of alcohol and drug-related problems in the Caribbean, 2) to create a nucleus of professionals and laypersons with basic skills for the prevention and treatment of substance abuse and 3) to change attitudes and behaviours, an important requisite for successful prevention and treatment work. 
After 40 years, CARIAD's annual residential twoweek substance abuse training programme has trained 2660 participants from 26 countries. These past participants were selected on the basis of their interest in substance abuse treatment and prevention. Participants are primarily recruited by solicited invitation through workplaces but many have been nominated by sponsors or self-selected. Table 1 shows the multi-disciplinary nature of CARIAD graduates. ment (1). However, the method of fostering the environment is usually not clearly described (3). This paper therefore explains how CARIAD fulfils the characteristics of a CoP, and the processes used to create and develop the learning community. The authors also look at the specific strategies and pedagogic techniques that foster collaborative knowledge construction and sharing.

Table 1: The multi-disciplinary nature of Caribbean Institute on Alcoholism and Other Drug Problems (CARIAD) graduates and faculty

\begin{tabular}{|c|c|c|}
\hline $\begin{array}{l}\text { CARIAD } \\
\text { graduates }\end{array}$ & $\begin{array}{l}\text { CARIAD graduates } \\
\text { in leadership roles }\end{array}$ & CARIAD faculty \\
\hline Doctors & Directors of national drug councils & Psychiatrists \\
\hline Nurses & Other staff of national drug councils & Psychologists \\
\hline Social workers & Directors of treatment programmes & Social workers \\
\hline Psychologists & Senior members in alcoholics anonymous & Teachers/educators \\
\hline Teachers & Senior members in narcotics anonymous & Community activists \\
\hline School counsellors & Trade unionists & $\begin{array}{l}\text { Employee assistance } \\
\text { Programme providers }\end{array}$ \\
\hline Police officers & Personnel managers & $\begin{array}{l}\text { Addiction counsellors } \\
\text { (Resource persons with lived experiences) }\end{array}$ \\
\hline Prison officers & Other leaders in healthcare & \\
\hline Clergymen & Other leaders in policy development & \\
\hline
\end{tabular}

A recent evaluation of the programme indicated that participants evaluated CARIAD as being effective in meeting its training objectives and positively impacting their professional practice (Reid et al 2014, under review). This paper describes the specific components of the CARIAD programme and explains how certain strategies and pedagogic techniques may be contributing to its success.

\section{Methodological principles of CARIAD}

The CARIAD programme is developed based on the principles of a community of practice (CoP). Communities of practice are defined by Wenger et al as "groups of people who share a concern, a set of problems or a passion about a topic, and who deepen their knowledge and expertise in this area by interacting in an ongoing basis" (1). The concept of a CoP was originally developed by Lave and Wenger who suggested that learning takes place in social relationships rather than through the simple acquisition of knowledge (2). Learning in a community of practice is a collective responsibility that addresses the tacit and dynamic aspects of knowledge creation and sharing, not limited by formal structures.

Wenger et al (1) identified three necessary characteristics of CoPs: 1) the domain or focus of interest and learning that creates the identity of the members of the CoP, 2) the community or social structure that facilitates learning through interactions and relationships with others and 3) practice, the specific knowledge that the community shares, develops and maintains. A well developed $\mathrm{CoP}$ provides an environment that facilitates learning and knowledge develop-

\section{RESULTS}

\section{Core programme components}

Four major components characterize CARIAD's approach to substance abuse training: plenary sessions, small group discussions, specialized group discussions and a focus on self-help groups.

Plenary sessions: Participants engage in 21 ninety-minute interactive plenary sessions, delivered by international substance abuse experts who provide evidence-based information, and regional experts who present substance abuse information in the sociocultural context of the Caribbean. Faculty is multi-disciplinary (Table 1). Sessions cover a broad scope of topics (Table 2), and are supported by technology including locally produced video presentations and teaching videos developed by CARIAD. Participants are invited to screen the content for relevance to socio-economic and cultural realities and to share insights with faculty and fellow participants within the small group sessions. Table 2: Summary of topics covered in Caribbean Institute on
Alcoholism and Other Drug Problems plenary sessions

\section{Topic categories}

The effects of psychoactive substances

The nature of addiction

Substance abuse aetiology

Substance abuse in specialized populations

Treatment interventions

An inside view into addiction

Relapse prevention

Prevention strategies

Community empowerment 
Small group discussions: The programme includes seven ninety-minute small group sessions aimed at discussing and consolidating the content of the plenary sessions, and introducing new topics for discussion (Table 3). Participants are organized into multidisciplinary groups that include a range of professions, nationalities, and a mix of genders and persons with lived experience. A group leader and rapporteur are blindly assigned to direct each group and accurately document ideas and discussions, consistent with written instructions given on their roles. Leaders ensure that the group remains on target, and involve all members without dominance or influence by anyone. The rapporteur reports back in the final plenary session, an activity that is valued by exempting rapporteurs from the final paper necessary for completion of the programme. treatment method in the Caribbean (4). A unique element of the CARIAD programme is participant observation in an open self-help group. In this setting, the group comprises persons in various stages of recovery from alcohol, marijuana and/or crack cocaine. Participants experience the intimacy of the self-help group that comes through self-disclosure. Understanding the dynamics from the perspective of livedexperience fosters a deeper understanding of substance use disorders, removal of stereotyping and negative counter transference, and overall helps with development of a sense of personal mission, identity and commitment to service. A plenary session devoted to a detailed understanding of the personal histories of alcoholics and drug addicts further augments these gains.

\begin{tabular}{lll} 
Table 3: & $\begin{array}{l}\text { Topics for Caribbean Institute on Alcoholism and Other Drug Problems small group } \\
\text { discussions }\end{array}$ \\
\hline Topics & \multicolumn{1}{c}{ Week 1 } & \multicolumn{1}{c}{ Week 2 } \\
\hline & $\begin{array}{l}\text { Drinking and drug practices in my region } \\
\text { Youth, alcohol and drugs } \\
\text { Other addictions }\end{array}$ & $\begin{array}{l}\text { Alternative approaches to treatment } \\
\text { Approach to the family } \\
\text { Stress management }\end{array}$ \\
& Self-help groups & \\
\hline
\end{tabular}

Small groups are designed to stimulate reflection and sharing of experiences with other group members, along with a faculty member who ensures accurate learning and is also the beneficiary of participants' experiences. Discussions incorporate personal, social and professional experiences and facilitate sharing of sociocultural, innovative approaches to treatment and prevention, and experiences on optimizing limited resources.

One of the elements which serves to strengthen the dynamics of the small groups is the planning and practice that goes into an event of cultural sharing scheduled for the end of the programme. The creation of authentic vignettes and role playing within the sector serves to remind participants that they bring a wealth of experience and a vast cultural repertoire to the field of substance abuse.

Specialized group discussions: The CARIAD programme also includes small group discussions on special interest topics, led by faculty experts who target the development of specific knowledge or skills. Participants self-select into three groups depending on the desired area of skill individual substance abuse counselling, Caribbean substance abuse prevention or harm reduction in the Caribbean.

These special interest groups are also intended to stimulate reflection and sharing of experiences but with emphasis on the faculty sharing expertise and discussing strategies to build skills and practice. These groups help to create standards of good practice.

Focus on a twelve-step self-help approach to treatment: Alcoholics Anonymous (AA) is a successful substance abuse
In addition, the structure of the CARIAD programme is significant for two other components:

Residential learning community: For the duration of the programme, all participants, permanent and visiting faculty, administrative staff and resource persons live and socialize together, and are encouraged to engage in informal discussions. Participants draw on faculty, resource persons and each other for problem-solving, new information and unprompted learning.

Promotion of reflexivity: The final activity of the programme is the wrap-up session which invites every student to verbally describe and analyse their experience, promoting reflexivity. Sharing typically identifies three main points: 1) how the programme helped to modify their future practice in substance abuse through the development of knowledge and skills, 2) a new appreciation of their role, responsibility and potential impact in the field and 3) the value of the personal relationships and networking that were established. The first two are consistent with Teekman's reflective thinking for learning and reflective thinking for critical inquiry (5), both of which work to improve practice and are expressed not only at the wrap-up session but through the subject-based reports that are written as a requirement for completion of the programme.

All of these elements operate in a harmonized manner, and contribute to an effective system for pedagogic learning, and a sense of commitment and identity which transcends profession. 


\section{DISCUSSION}

Caribbean Institute on Alcoholism and Other Drug Problems is the longest running substance abuse training programme in the Caribbean, and based on a recent evaluation (Reid et al 2014, under review), is effective in producing a network of graduates with the knowledge, skills and motivation to lead in the field of substance abuse in the Caribbean. Caribbean Institute on Alcoholism and Other Drug Problems had a positive impact on participants' professional practice, and facilitated training and sharing of knowledge with colleagues and communities. This demands a deconstruction of the programme components to critically analyse what might be contributing to the success of this programme.

Formed through a recognition of the need for substance abuse training in the Caribbean, CARIAD brings together in one location a professionally diverse group of individuals from various Caribbean countries, all of whom have a vested interest in reducing substance use and abuse. The core elements of CARIAD allow participants, all of whom are practitioners, to engage in joint activities and critical discussions, and build relationships which allow them to learn from each other on the common domain of substance abuse in the Caribbean. Caribbean Institute on Alcoholism and Other Drug Problems thus meets the requirements of a community of practice.

Whilst providing the traditional didactic opportunities with reliable content experts, CARIAD also gives emphasis to practical challenges in efforts to apply identified best practices. Plenary sessions afford the most recent knowledge in substance abuse as well as Caribbean specific challenges and strategies.

Wenger states, "Successful communities of practice provide enough structured activities for members to build a pace of participation; however, they also provide opportunities for members to share creative ideas and opportunities" (1). Through small group activities and specialized group sessions, CARIAD provides ample opportunities for social interaction, knowledge creation and sharing within the groups. Deliberate promotion of participant interactivity, including planning for the final cultural event, results in early cohesion in the groups, an openness to sharing both knowledge and gaps in knowledge, and an intention to change practice. The cultural show gives participants an opportunity to showcase their learning, revealing cultural insights into local and regional expressions of substance abuse challenges. Because groups are composed of differing professions, levels of knowledge and levels of professional expertise and experience, learning is facilitated among all participants (6), and even from participant to faculty.

The concern for individual and minority views is one of five features commonly identified by contemporary theorists exploring community (7). In CARIAD's structured environment, the group leaders of small multi-disciplinary, multi-national groups are given the responsibility of ensuring the involvement of all participants, enabling participants to easily move from periphery to full participation.

Being mandated to report back to the large group gives legitimacy to the exercise. Atherton (8) has lamented that reporting back after small group discussions is undervalued. At CARIAD, the rapporteur's successful completion of the programme depends on efficient reporting of the group discussions which adds value and seriousness to the group activities. The presence of a faculty member in each group ensures that no group is devalued at the time of presentation by corrections that need to be made, and empowers the groups as knowledge-sharers.

In a community of practice, informal learning complements formal learning. In fact, Boud (9) suggests that informal interactions are a predominant way of learning in the academic professions. According to Wenger (1), the key to informal learning is the social participation within the community. Being a residential community, CARIAD gives participants significant opportunity for informal learning among faculty, participants and resource persons with lived experience.

Promoting a sense of identity among participants is an important function of a CoP. By the end of CARIAD, participants acquire a professional identity of skilled practitioners of substance abuse prevention and treatment. Several unique elements in the CARIAD programming help to promote a collective identity, including the participant observation of a twelve-step self-help group, and the reflexive sharing at the end of the programme.

The self-help movement shares characteristics with a $\mathrm{CoP}$ and reinforces these dynamics among the CARIAD participants who observe a meeting, assisting in the building of a community identity. Participants reflect positively on the impact of the experience on promoting introspection and reflection on their professions. In developing an identity, attitudes and behaviours are changed and this is an explicit objective of the CARIAD programme.

Reflection is described as an important component of professionals' education and training (10). In a professional context, reflexivity is seen as challenging the practices, roles, beliefs and values of practitioners and promoting learning and re-development of practice (11). When reflexivity is deliberately structured, learning processes are made more explicit (12). The CARIAD programme promotes reflexivity through its various components and the learning and restructuring of practice culminate in the expressions at the wrap-up session.

This CoP is not without its limitations. The selection by employers and sponsors of participants who are unwilling or uninterested in the domain poses a challenge. When people are forced to participate, they may not have experiences, or be willing to share their experiences. This may result in lowering of the quality of delivery (13).

Participants between 2003 and 2012 were asked to comment on how CARIAD could best address emerging 
substance abuse trends in the Caribbean. Although CARIAD was recognized as a vehicle for significant learning and practice change, the alumni also perceived the absence of structured continuity and the diminution of what could be accomplished by graduates over time. Boud and Middleton (14) explain that a CoP may be strongly framed when transmission of knowledge occurs closely between members, or weakly framed when transmission of knowledge is less frequent or consistent. Caribbean Institute on Alcoholism and Other Drug Problems after the two-week programme goes drastically from strongly framed to weakly framed. Participants appear to recognize this shift and made logical demands for continued networking opportunities, knowledge exchange and increased communication among alumni. They also desired greater empowerment of CARIAD alumni to play a more prominent role in the management of alcohol and drug abuse programmes and policies in the Caribbean, indicating clearly a perception of ongoing relevance for the institute, despite great limitations in resources. In effect, it seems that participants want CARIAD to remain a strongly framed community of practice. Caribbean Institute on Alcoholism and Other Drug Problems therefore requires more external elements in order to emerge and grow as a dynamic self-sustaining, regional social structure. Networking events should promote a collective responsibility for managing the knowledge that was obtained during the CARIAD programme.

A challenge of growing concern is the steadily declining number of regional participants, reportedly related to the steadily declining sources of funding. The proportion of regional participants from outside Trinidad and Tobago went from $64.5 \%$ in 1996 to $4 \%$ in 2012 . This lack of representation from diverse countries poses a significant threat to the current methodology of teaching and to the successful implementation of a community of practice and must be addressed with urgency.

The success of CARIAD as a regional training programme may be related to its success as a Caribbean community of practice for substance abuse. By providing a platform for cultural sharing, CARIAD uniquely gives participants an opportunity to reveal cultural insights into local and regional expressions of substance abuse challenges. Caribbean Institute on Alcoholism and Other Drug Problems would do well to sustain a community of practice, generating and maintaining ongoing participation and collaboration by all graduates. This can potentially serve to create new strategies for advancing the region in the area of substance abuse.

\section{REFERENCES}

1. Wenger E, McDermott RA, Snyder W. Cultivating communities of practice. Boston, MA: Harvard Business School Press; 2002.

2. Lave J, Wenger E. Situated learning: legitimate peripheral participation. Cambridge: Cambridge University Press; 1991.

3. Li LC, Grimshaw JM, Nielsen C, Judd M, Coyte PC, Graham ID. Use of communities of practice in business and health care sectors: a systematic review. Implement Sci 2009; 4: 27. doi: 10.1186/1748-59084-27.

4. Beaubrun MH. Treatment of alcoholism in Trinidad and Tobago, 195665. Br J Psychiatry 1967; 113: 643-58.

5. Teekman B. Exploring reflective thinking in nursing practice. J Adv Nurs 2000; 31: 1125-35.

6. Lathlean J, le May A. Communities of practice: an opportunity for interagency working. J Clin Nurs 2002; 11: 394-8.

7. Westheimer J. Communities and consequences: an inquiry into ideology and practice in teachers' professional work. Educ Admin Q 1999; 35: 71-105.

8. Atherton JS. Learning and teaching; groups reporting back [Internet]. UK: National Teaching Fellowship Scheme; 2013. Available from: http://www.learningandteaching.info/teaching/groups_reporting back.htm

9. Boud D. Situating academic development in professional work: using peer learning. Int J Acad Dev 1999; 4: 3-10.

10. Mann K, Gordon J, MacLeod A. Reflection and reflective practice in health professions education: a systematic review. Adv Health Sci Educ Theory Pract 2009; 14: 595-621.

11. Bolam B, Chamberlain K. Professionalization and reflexivity in critical health psychology practice. J Health Psychol 2003; 8: 215-18.

12. Black PE, Plowright D. Exploring pharmacists' views about the contribution that reflective learning can make to the development of professional practice. Int J Pharm Pract 2007; 15: 149-55.

13. Whalley M, Chandler R, John K, Reid L, Thorpe S, Everitt J. Developing and sustaining leadership learning communities: implications of NPQICL rollout for public policy local praxis. Eur Early Child Educ 2008; 16: 5-38.

14. Boud D, Middleton H. Learning from others at work: communities of practice and informal learning. J Workplace Learning 2003; 15: 194-202.

Submitted 13 Oct 2014

Accepted 27 Oct 2014

Published 16 Mar 2015

Online: http://www.mona.uwi.edu/wimjopen/article/1624

(C) Reid et al 2015

This is an open access article made freely available under Creative Commons Attribution 4.0 International (CC BY 4.0). Users are free to share, copy and adapt this work as long as the copyright holder (author) is appropriately and correctly credited. See http:// creativecommons.org/licences/by/4.0/deed.en_us for more information. 